\title{
Utilization of social media communities for caregiver information support in stroke recovery: An analysis of content and interactions
}

Elton H. Lobo ${ }^{1 *, 2}$, Tara Johnson ${ }^{2,3}$, Anne Frølich ${ }^{2,4}$, Finn Kensing ${ }^{5}$, Lene J. Rasmussen $^{6,7}$, Sarah M. Hosking ${ }^{3}$, Amy T Page ${ }^{8,9}$, Patricia M. Livingston ${ }^{3}$, Sheikh Mohammed Shariful Islam ${ }^{10}$, John Grundy ${ }^{11}$, Mohamed Abdelrazek ${ }^{1}$

${ }^{1}$ School of Information Technology, Deakin University, Geelong, VIC, Australia;

${ }^{2}$ Department of Public Health, University of Copenhagen, Copenhagen, Denmark;

${ }^{3}$ Faculty of Health, Deakin University, Geelong, VIC, Australia;

${ }^{4}$ Innovation and Research Centre for Multimorbidity, Slagelse Hospital, Region Zealand, Denmark;

${ }^{5}$ Department of Computer Science, University of Copenhagen, Copenhagen, Denmark;

${ }^{6}$ Department of Cellular and Molecular Medicine, University of Copenhagen, Copenhagen, Denmark;

${ }^{7}$ Center for Healthy Aging, University of Copenhagen, Copenhagen, Denmark;

${ }^{8}$ Pharmacy Department, Alfred Health, VIC, Australia;

${ }^{9}$ Centre for medicine Use and Safety, Monash University, VIC, Australia;

${ }^{10}$ Institute for Physical Activity and Nutrition (IPAN), Deakin University, Geelong, Australia;

${ }^{11}$ Faculty of Information Technology, Monash University, VIC, Australia

\section{*Corresponding author:}

Email: elobo@deakin.edu.au (EL) 


\section{Abstract}

2 Background: Caregivers often use the internet to access information related to stroke care to

3 improve preparedness, thereby reducing uncertainty and enhancing the quality of care.

4 Method: Social media communities used by caregivers of people affected by stroke were

5 identified using popular keywords searched for using Google. Communities were filtered based

6 on their ability to provide support to caregivers. Data from the included communities were

7 extracted and analysed to determine the content and level of interaction.

8 Results: There was a significant rise in the use of social media by caregivers of people affected

9 by stroke. The most popular social media communities were charitable and governmental organizations with the highest user interaction - this was for topics related to stroke prevention,

11 signs and symptoms, and caregiver self-care delivered through video-based resources.

12 Conclusion: Findings show the ability of social media to support stroke caregiver needs and 13 practices that should be considered to increase their interaction and support.

Keywords: Social media; Community; Facebook; Twitter; Google; Information; Interaction

\section{Introduction}

Stroke is the leading cause of dependency and disability worldwide [1], resulting in family caregivers providing substantial care to people with stroke [2]. Family caregivers, generally known as informal caregivers [3] are responsible for assisting with daily activities, including mobilization, toileting, bathing, transportation, and navigating the health care system [4]. 
22 Despite their key role in care, many caregivers feel unprepared [5], leading to psychological, social, physical, and financial strains [6].

Family (or informal) caregivers have varying needs for education and support during the stroke care trajectory [7]. Yet, to date, standard clinical practice guidelines have not considered programs to ensure caregiver education and support [8]. The most common form of information received by caregivers at the hospital included booklets and pamphlets, which caregivers have reported to be very basic or out of date [9]. Caregivers may attempt to source alternate information sources to improve preparedness to reduce uncertainty and enhance recovery [10]. In the past, caregivers have predominately used the internet (or online) sources to access information related to stroke care [11-13]. The internet is changing how health information is accessed [14], thereby influencing individuals' knowledge, attitudes, and beliefs towards a specific health behaviour [15]. As a result, the trend towards internet use for health information purposes has been significantly rising [16]. A cross-sectional study by Naqvi, Montiel [17] reported over $96.8 \%$ of caregivers having access to the internet to generally browse web pages $(84.6 \%)$ and access their emails $(89.4 \%)$.

Today, in the era of Web 2.0, social media such as Facebook and Twitter has changed the landscape in health care information delivery $[16,18]$. Social media can empower people to adopt a healthy lifestyle and help improve health management and decision-making processes [19]. Furthermore, social media creates an unprecedented opportunity to enhance the quality of care by mobilizing many social media users and enabling the users to generate a large amount of content [19]. The content generated is in the form of user health care knowledge, experiences, symptoms, health care products, doctors, and medicines in easily accessible formats, such as images, text, and videos [18]. 
45

46

47

\section{Method}

\section{Study Design}

60 Our study consisted of a mixed-method approach to answer identified research aims. The

61 mixed methods approach is a type of research where a researcher or group of researchers

Social media use has provided organizations and individuals with an openly accessible platform to engage actively and participate in healthcare [20]. However, very little is known about its potential benefit to caregiving and its ability to interact with the caregiver actively. This study presents three key aims. This study aims to:

1. Investigate frequency of searches for stroke-related terms over time using Google Insights and Google Trends.

2. Identify the information content available to caregivers on popular informationsupport-based social media platforms (i.e., Facebook and Twitter) to support their needs and activities.

3. Understand the levels of interaction for the different social media posts identified through the likes, comments, and shares by content types (i.e., image, video, link, or text).

combine elements of quantitative and qualitative methods (e.g. use of quantitative and qualitative viewpoints for data collection, analysis and inference techniques) to provide a broad understanding of the research problem [21]. For example, to investigate the frequency of stroke terms, a quantitative analysis was conducted to determine the online activity of people interested in stroke recovery and care using tools such as Google Trends and Google Insights. Google Trends and Google Insights provide a platform for individuals to investigate its users' search behaviour throughout time based on a relative cumulative search volume score from 0- 
69100 , which is the ratio of single search term volume to all possible searches. A qualitative 70 analysis was used to analyse the information content using a thematic synthesis approach.

71 Finally, the levels of interaction were identified through a quantitative statistical analysis of 72 likes, comments, and shares based on the different content types.

\section{Identifying relevant communities}

The identification of relevant social media communities (or groups) in stroke recovery involved multiple steps. Initially, we identified the relevant search keywords used based on discussions with topic experts and electronic database searches. We tested the keywords on Google Insights and Google Trends to determine their relevance to individuals around the world in stroke recovery and care based on their searching behaviour. Finally, we performed individual searches on two popular social media platforms (i.e., Facebook and Twitter).

A search of social media platforms (i.e., Facebook and Twitter) was conducted from December 2020 to January 2021 and was limited to those available in the English language. Moreover, the search included only communities made public by the administrator (or did not require permissions to be accessed by the user).

Table 1. Inclusion and Exclusion Criteria used to filter Social Media Communities

\begin{tabular}{|l|l|}
\hline Inclusion Criteria & Exclusion Criteria \\
\hline$\bullet \quad$ Considers Caregivers of Stroke described & $\bullet \quad$ Does not include Caregivers of Stroke \\
through its description or content & $\bullet \quad$ Blocks Users from Replying to Posts \\
- Provides Information regarding Stroke & \\
\hline Supports User Interaction on Posts & \\
\hline
\end{tabular}




\section{Community selection}

89 Initially, the researchers used a custom-built web form to manually extract information

90 from all social media communities, including community names, descriptions, links, number

91 of followers (or likes), and several posts, and store the data in a MySQL database. The

92 communities identified were then filtered based on the inclusion and exclusion criteria

93 described in Table 1.

94

95 Analysis the findings

96 The analysis process involved a multi-stage data extraction and management process using

97 a custom-built python scraper consisting of all the community page links and outputs findings

98 to a MySQL database. The data was then extracted as a Microsoft Excel file and coded

99 independently using QSR NVivo 12 by two researchers based on a three-stage thematic

100 synthesis approach, involving: 'line by line' coding of text, development of descriptive themes,

101 and generation of analytical themes [22]. All posts unrelated to the caregiver and/or posts that

102 did not provide information support (e.g., advertisements, event photos, news articles, research

103 studies, etc.) were excluded from the study. Additionally, descriptive characteristics data from

104 the communities (such as community name, origin, published date, and basic information) and

105 interaction data (such as likes and comments) were charted by one researcher to answer the

106 specific research aims. 


\section{Collating and summarizing}

109 Both qualitative and quantitative findings were collated and summarized to answer the

110 research questions resulting in the descriptive numerical summary and thematic analysis. The

111 predefined descriptive classification applied to the initial coding of the communities include;

\section{2 a. Community Demographics}

113 - Year Published - to understand the growth in online communities over the past few

114 decades.

115 - Community location - to understand the target population

116 - Community affiliation - to know if the content created is by people working in the stroke

117 domain

118 b. Community Purpose - to understand the purpose of the community through the

119 community description

120 c. Information Support - to understand the type of information provided to the caregiver in

121 the post (i.e., disease, patient care management, self-care, etc.) and the method of delivery

122 (i.e., text, image, video, or link) using a thematic analysis technique

\section{3 d. Community Interaction}

124 - Post purpose - to understand the information type required by the user

125 - Likes, followers, reactions, and comments - to understand user interaction based on the

$126 \quad$ post purpose 


\section{Results}

\section{Digital Interest Regarding Stroke}

130 Overall, 94 keywords were identified from discussions with topic experts and electronic

131 database searches. Of these 94 keywords, 15 keywords were based on stroke disease and its

132 definitions, 25 keywords were related to the signs \& symptoms of stroke, 37 keywords included

133 different medications used in stroke and 17 keywords focused on aspects related to recovery \&

134 care.

135 Findings from the Google Trends and Google Insights searches demonstrated an apparent 136 increase in the cumulative search volumes for the terms identified through discussions with 137 topic experts and electronic database searches over the past ten years (Fig 1). The rise in the 138 cumulative search volume was 12.4 between January 2011 and December 2020 identified by:

$$
a_{i j}=\frac{\sum k_{i}}{N_{i j}}
$$

140 Where $a_{i j}$ is the average cumulative search volume for each topic $(j)$ each year $(i), k$ is the

141 cumulative search volume acquired from Google Trends and Insights for all the keywords

142 associated with the topic for year $i, N$ is the total number of keywords in the topic $(j)$ for year $i, i$ is the year ranging from 1 to 10 and $j$ is the topic ranging from 1 to 4 .

$$
Y_{i}=\frac{\sum_{j=1}^{j=4} a_{i j}}{4}
$$

where $Y_{i}$ is the average cumulative search volume for all topics $\left(a_{i j}\right)$ in year $i$ ranging from 1

$$
A=Y_{10}-Y_{1}
$$


148 where $A$ is the rise in the cumulative search volume between the Tenth $\left(Y_{10}\right)$ and First $\left(Y_{1}\right)$ Years (i.e. January 2011 and December 2020)

150

151 Topics including 'stroke definition' and 'stroke recovery' were the most commonly searched 152 during the ten years. Issues such as 'signs \& symptoms of stroke', and stroke medication have 153 had a significant rise in searches during the past four years.

154

155

160 (or usage) activity as extracted from Google Trends and Google Insights. The ten most

161 frequently used keywords were selected based on their cumulative search volume over the past

162 year.

Fig 1. Cumulative Search Volume from January 2011 to December 2020 for Stroke Related Topics used in this Study

\section{Identification of relevant keywords}

Table 2 presents the ten most commonly searched terms identified by the online search

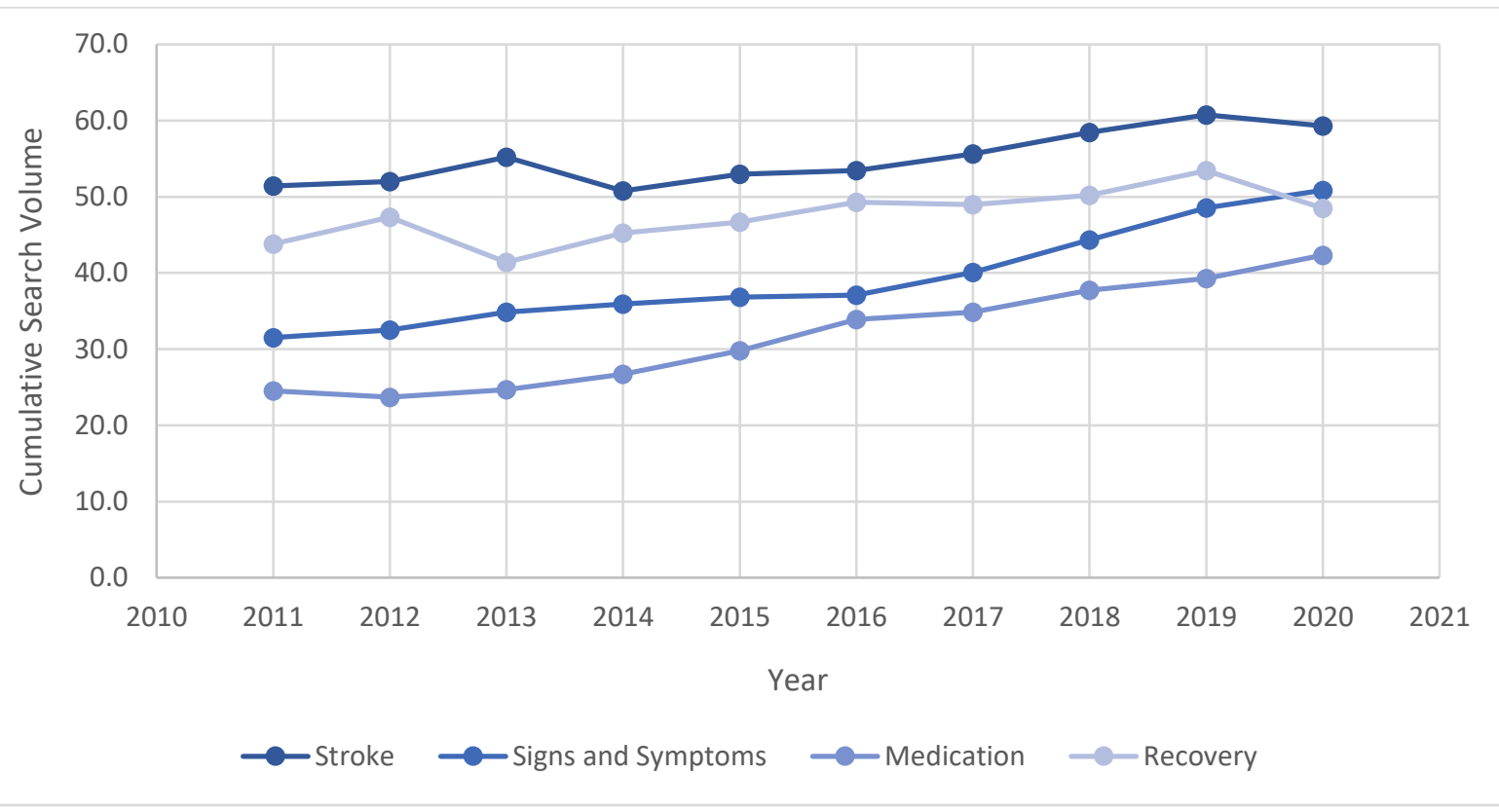


Table 2. Ten Most Commonly used Keywords in Stroke identified through Google Trends

\begin{tabular}{|l|c|}
\hline Keyword & Cumulative Search Volume \\
\hline Stroke & 85.3 \\
\hline Stroke Care & 81.6 \\
\hline Stroke Recovery & 76.8 \\
\hline Apoplexy & 76.3 \\
\hline Cerebrovascular Accident & 75.6 \\
\hline Stroke Unit & 75.1 \\
\hline Traumatic Brain Injury & 74.5 \\
\hline Lacunar Infarct & 74.2 \\
\hline Stroke Medication & 73.6 \\
\hline Aphasia & 73.1 \\
\hline
\end{tabular}

165

\section{Social media communities}

The combined search strategies identified 352 social media communities using the

168 keywords identified in Table 2, which were then screened for eligibility using the inclusion

169 and exclusion criteria demonstrated in Table 1. Out of the 352 social media communities, 111

170 were excluded as they were not related to stroke patient caregivers, 23 were not accessible to

171 the public, 17 were not associated with stroke, and 3 were not available in English. Overall,

172198 social media communities were included in the study, as shown in Table 3.

174 Table 3. Social media communities included in the Review

\begin{tabular}{|ll|l|}
\hline \multicolumn{3}{|c|}{ Facebook (n=169) } \\
\hline - Association for the Rehabilitation of the & - Minnesota Brain Injury Alliance/Minnesota \\
Brain Injured & & Stroke Association \\
- Stroke Recovery Foundation & Suncoast Aphasia Support Group \\
- United Stroke Alliance & Oceanside Stroke Recovery Society \\
- American Stroke Association & - Orillia Stroke Survivor and Caregiver \\
- Stroke Association & & Support Group \\
- Stroke Foundation & Delta Stroke Recovery Society \\
- National Aphasia Association & - Pittsburgh Aphasia Community \\
- Aphasia Recovery Connection & StrokeEd \\
- American Stroke Foundation & Aphasia Lab-USC \\
- Stroke Association NI & BRAIN Lab: Brain Research for Aphasia and \\
- Stroke Association South West & & Intensive Neurorehabilitation Lab \\
- Stroke Survivors Foundation & Aphasia CRE \\
\hline
\end{tabular}


- Aphasia Ireland

- Stroke Association East of England

- Aphasia Network

- Aphasia Nova Scotia

- Stroke Association London

- Stroke Family Awareness

- Bright Spot Pediatric Stroke

- American Aphasia Society

- FAST Stroke Awareness

- $\quad$ World Stroke Day Kenya 2017

- Stroke SA Inc

- Supporting Aphasia Fellowship Education Fellowship and Education

and

- Brain Injury Recovery Foundation

- Australian Aphasia Association

- Stroke Foundation of NZ

- Think Ahead Stroke

- Stroke Fighters

- Stroke Survivors Empowering Each Other (SSEEO)

- Singapore National Stroke Association

- BINA Stroke \& Brain Injury Assistance

- Stroke Rehabilitation \& Healing, Inc.

- Calgary Aphasia Centre

- Stroke Support of Texas

- $\quad$ Stroke Help Network

- Aphasia NSW

- The Scott Coopersmith Stroke Awareness Foundation

- Brain injury \& Stroke Foundation KENYA

- Friends of Aphasia

- Retreat \& Refresh Stroke Camp

- Adler Aphasia Center

- Aphasia Center of California

- Living with Aphasia

- Talkback Association for Aphasia Inc

- Stroke Information Support Group

- Alberta Aphasia Camp

- Aphasia Centre of Ottawa

- Aphasia vzw

- Stroke Rehabilitation Ireland

- Stroke Caregivers

- Stroke Ownership \& Recovery

- Midwest Stroke support group for survivors and caregivers

- Stroke,tbi,and their,caregivers

- The Other Stroke Talk for survivors, caregivers and anyone who wants to be

- Support for Caregivers of Stroke Patients

- Malaysian Stroke Rehabilitation

- Stroke \& Neuro Intervention

- Aphasia SG
- STROKE-The Road to Recovery

- World Stroke Campaign

- Stroke Special Interest Group

- University of Michigan Aphasia Program (UMAP)

- Stroke Rehabilitation Research

- Stroke and Cerebrovascular Accident Education

- Triangle Aphasia Project, Unlimited

- Aphasia Connections

- Priority Research Centre for Stroke and Brain Injury

- The Big Sky Aphasia Program

- Purdue University Aphasia Group

- Hazard \& Surrounding Area Stroke Survivor \& Caregiver Support Group

- Spot Stroke

- Kathi Naumann -Stroke Support \& Survival Guide

- The Aphasia Cafe by Dr. Dawn McGuire

- Stroke Awareness

- Raising Stroke Awareness

- Stroke Awareness for Everyone

- Stroke Prevention

- Aphasia Awareness

- Stroke therapy tricks for stroke survivors

- Stroke Group

- Canadian Aphasia Association

- Aphasia Awareness

- Stroke

- Stroke Cure

- Stroke Rehabilitation Awareness

- Stroke Caregiver

- Rehabilitation for Stroke

- TBI Hope \& Inspiration

- The Brain Fairy - Living with Brain Injury

- Aphasia Friendly Resources

- Stronger After Stroke Blog

- Stroke information

- Stroke Support

- Recovering from Brain Injury

- Stroke Recovery Tips

- Stroke Recovery: Stories from Patients, Doctors, Families and Caregivers

- Stroke

- GRASP - Geriatric Relearning After StrokeInduced Paralysis

- Caregiving for Stroke Survivors

- Teamconnor fundraising and brain injury/stroke awarness

- Stroke Survivor Caregivers

- Surviving A Stroke 


\begin{tabular}{|c|c|}
\hline $\begin{array}{l}\text { - } \\
\text { - } \text { and Cheshire } \\
\text { - } \text { AphasiaAccess } \\
\text { - Stroke Survivors } \\
\text { - Certified Stroke Rehabilitation Specialist } \\
\text { (CSRS) } \\
\text { Greenhills Stroke Rehabilitation Center } \\
\text { Ghana } \\
\text { - Stroke Rehabilitation } \\
\text { - Montgomery County Stroke Survivor, } \\
\text { - } \text { Caregiver, and Aphasia Support Group } \\
\text { - Stroke \& Neuro Rehabilitation for } \\
\text { - Stroke Rehabilitation Centre } \\
\text { - Stroke Awareness }\end{array}$ & $\begin{array}{l}\text { Center } \\
\text { ors Foundation } \\
\text { Center } \\
\text { ation NZ } \\
\text { argiver } \\
\text { lymouth } \\
\text { ery } \\
\text { oke Assistance \& Support } \\
\text { e NL } \\
\text { oke Support Group - SOSS } \\
\text { urselves }\end{array}$ \\
\hline
\end{tabular}




\section{Descriptive characteristics}

177 Out of the 198 social media communities, $141(71.2 \%)$ were available on Facebook and

$17857(28.8 \%)$ were available on Twitter. These communities were created by individuals $(\mathrm{n}=64$;

$17932.3 \%)$, charitable or non-profit organizations $(n=61 ; 30.8 \%)$, community centres $(n=24$;

$18012.1 \%)$, educational organizations $(n=20 ; 10.1 \%)$, medical centres $(n=13 ; 9.1 \%)$, small and

181 medium sized organizations $(\mathrm{n}=8 ; 4.0 \%)$ and governmental organizations $(\mathrm{n}=3 ; 1.5 \%)$

182 identified based on administrator affiliations and community descriptions as illustrated in Fig

183 2. The most popular groups, identified by the number of followers, were charitable

184 organizations and governmental organizations (Fig 3).

185 Across all social media platforms, Twitter was seen to have the highest average number

186 of followers and posts (7093.6 followers and 4828.7 posts), followed by Facebook (4202.8

187 followers and 579.6 posts) as shown in Fig 4. The earliest identified pages were published in

1882009 on both Twitter $(n=10 ; 5.1 \%)$ and Facebook $(n=5 ; 2.5 \%)$. Since 2009, both social media

189 platforms have witnessed a variation in the number of new stroke communities for caregivers

190 (Fig 5). 
191

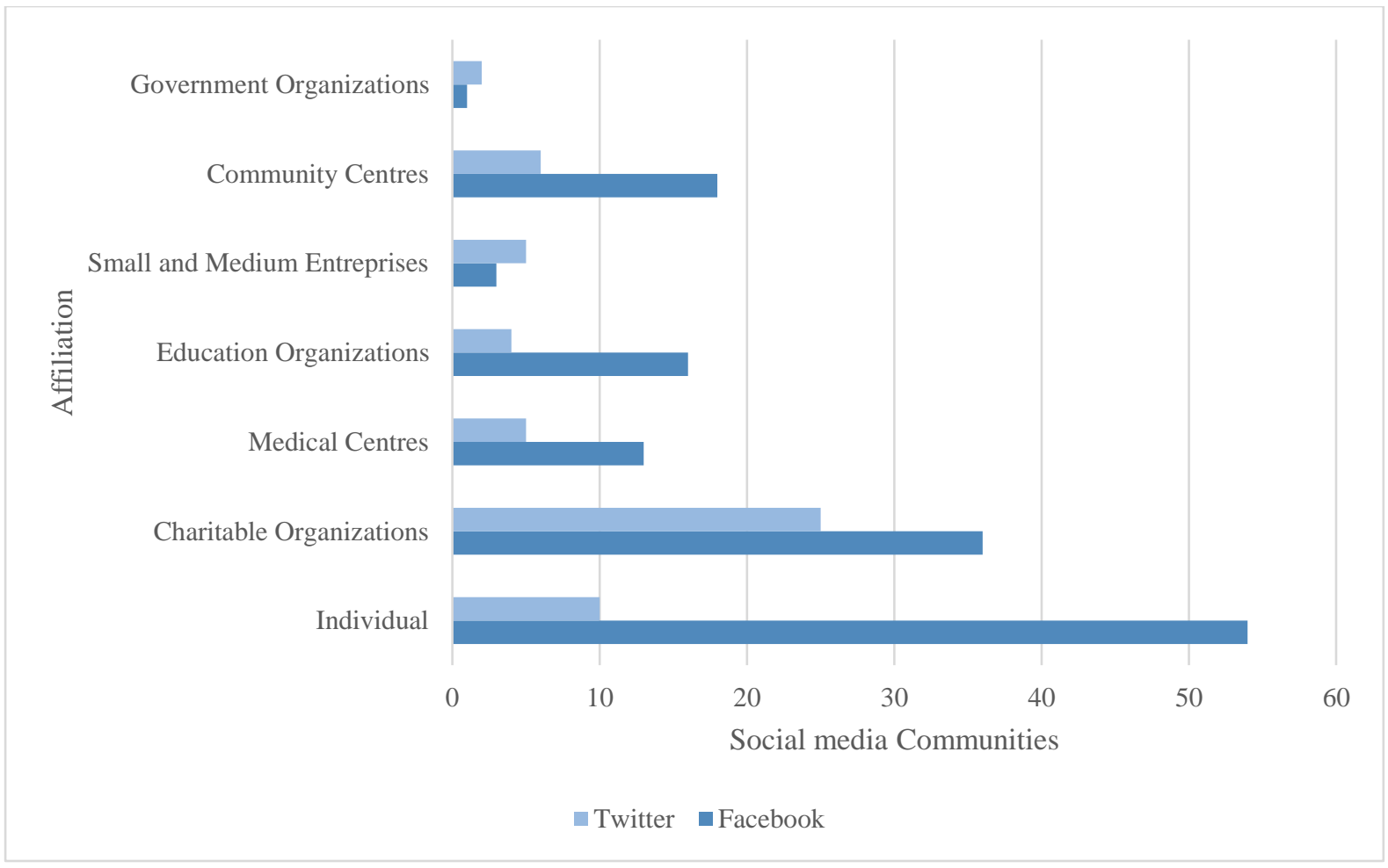

192 Fig 2. Social Media Communities by Affiliation

193

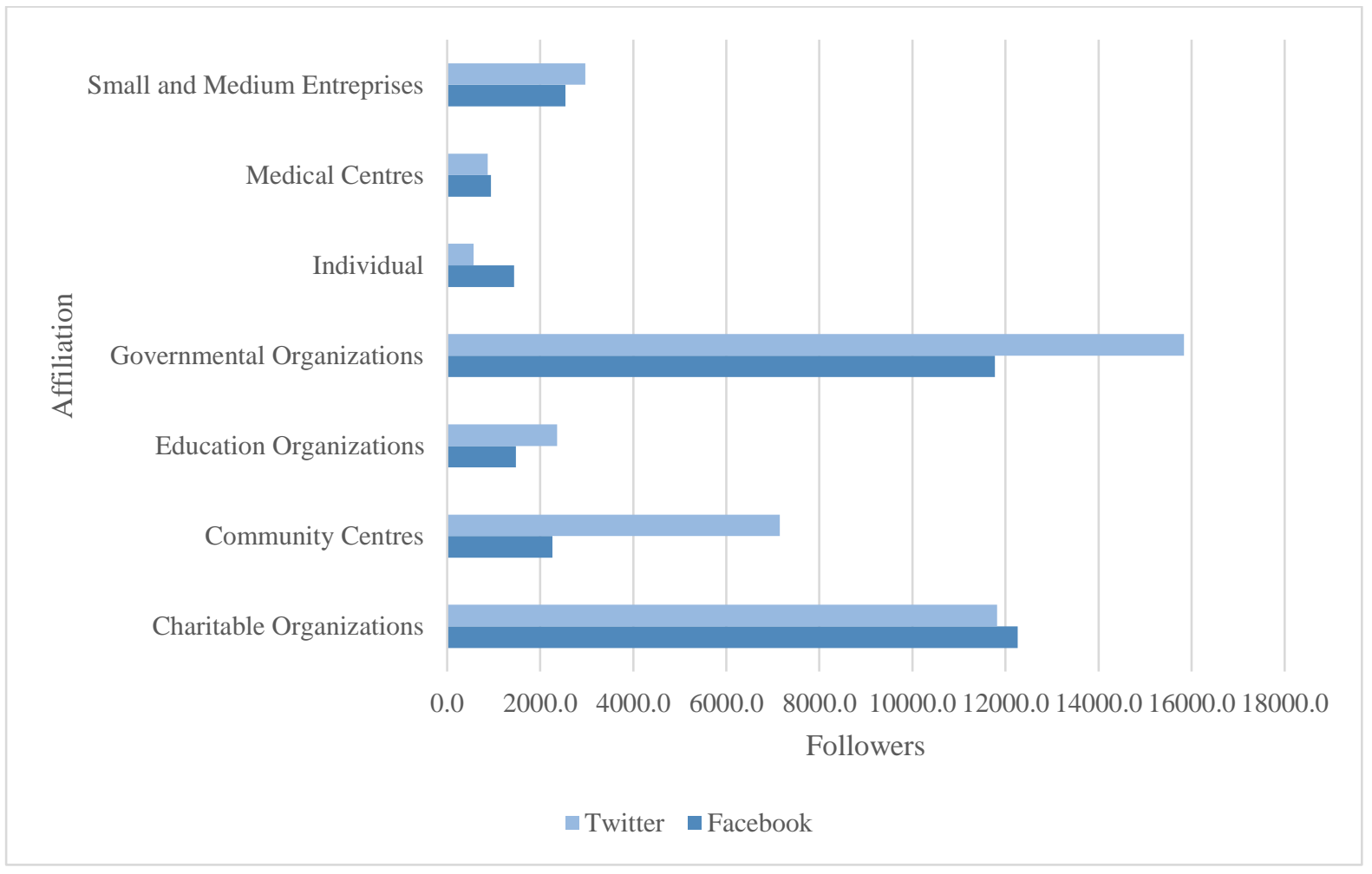

194 Fig 3. Social Media Communities by Followers and Affiliation 
195

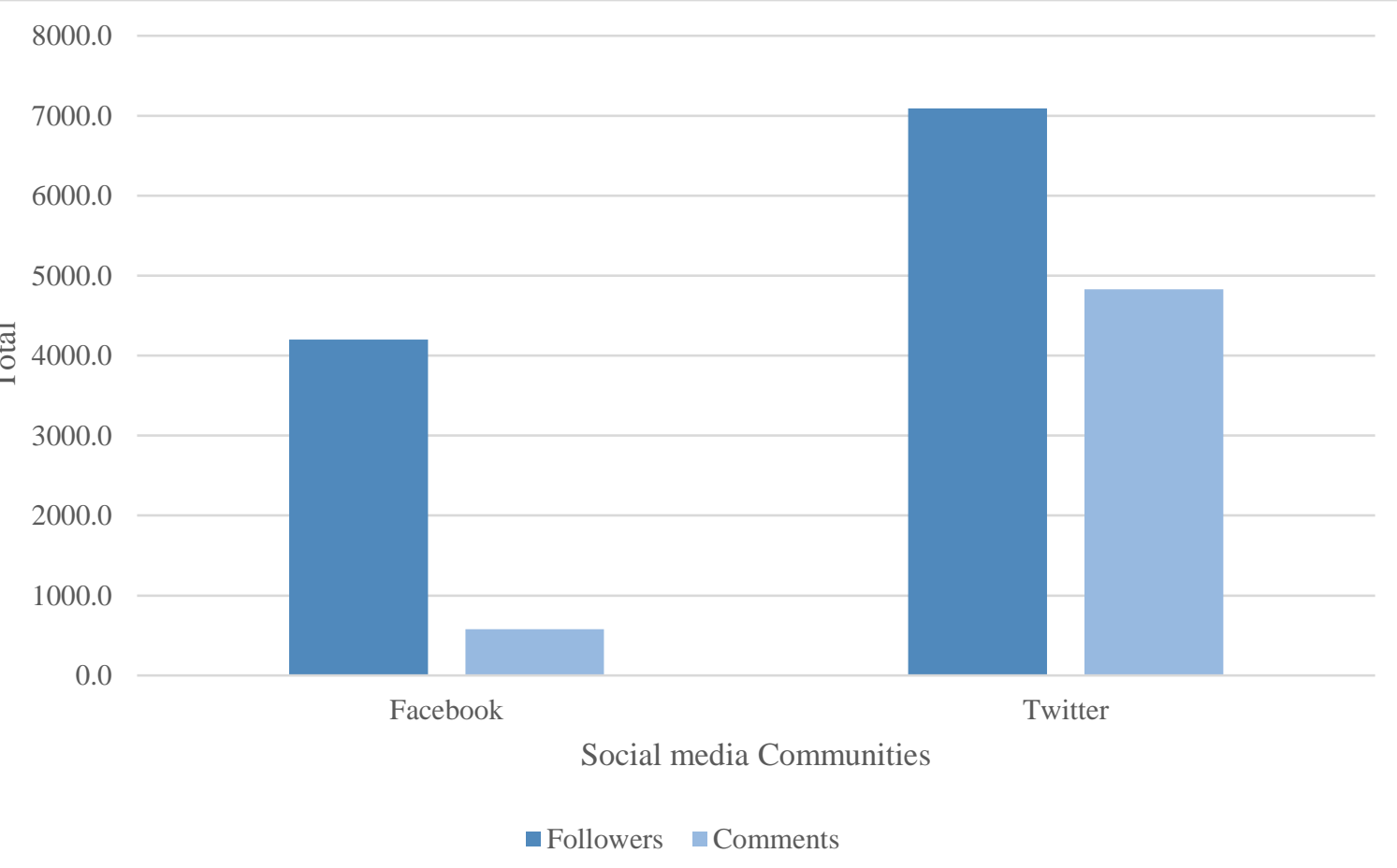

196 Fig 4. Social Media Communities by Followers and Posts

197

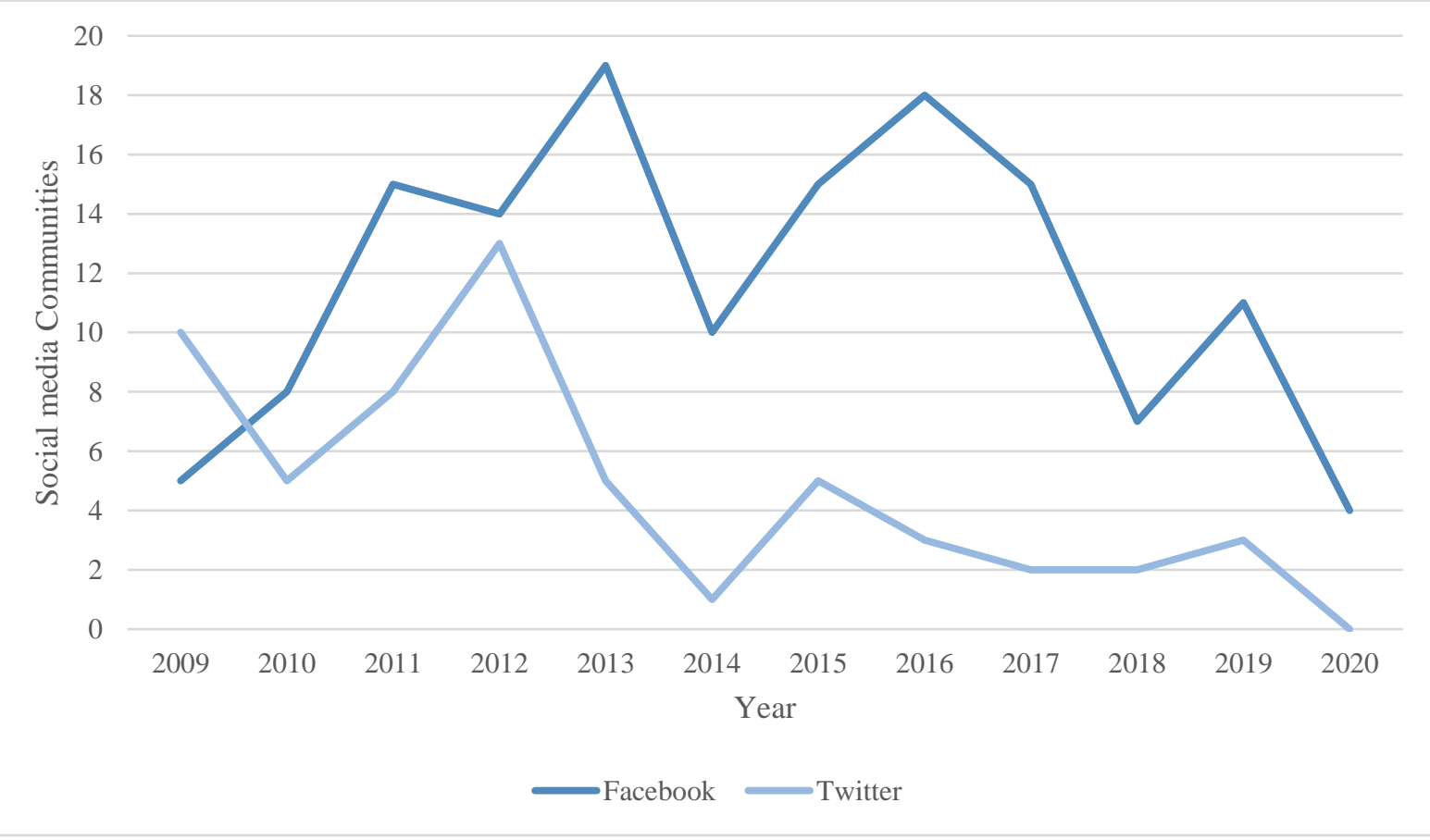

198 Fig 5. Variations in New Social Media Communities by Year 


\section{Community Purpose}

201 The analysis of the social media community description identified six prominent themes

202 (Fig 6) detailed below:

203

204

205

206

207

208

209

210

211

212

213

214

215

216

217

218

a. Support: Support-based social media communities were the most common community type $(n=81 ; 40.9 \%)$; these are intended to provide users with tools to support and share caregiving responsibilities. Moreover, these communities allowed users to join either virtual or local groups to promote emotional and psychological support.

b. Awareness: Communities in this theme $(n=59 ; 29.8 \%)$ intend to make the caregiver more aware of the tools and resources available locally to support the patient during care. It also allowed the caregiver to understand the risk factors and signs of a stroke to prepare them during a secondary stroke event.

c. Education: The education theme $(n=34 ; 17.2 \%)$ consisted of communities that share online books and resources intended to educate the caregiver on stroke-related topics, factors associated with its occurrence, secondary prevention techniques, management, support guidelines, medication resources, and similar issues. This was generally delivered in the form of text and video-based resources.

d. Advertising: These communities $(n=14 ; 7.1 \%)$ generally focused on advertising recovery products to support caregivers during care and ongoing research conducted at local universities to develop better care practices to support caregivers and their patients.

e. Motivation: Motivation $(n=8 ; 4.0 \%)$ oriented communities generally delivered this by caregivers and patients through personal stories and practices during recovery. Social media communities motivated their users through inspirational quotes and success stories.

f. Fundraising: The fundraising communities $(n=2 ; 1.0 \%)$ were either delivered by charitable organizations to support caregivers and their patients or by individual caregivers struggling to support patients due to financial constraints. The fundraising in charitable 
225 organizations involved links to fundraising campaigns and campaign invites to events 226 conducted locally.

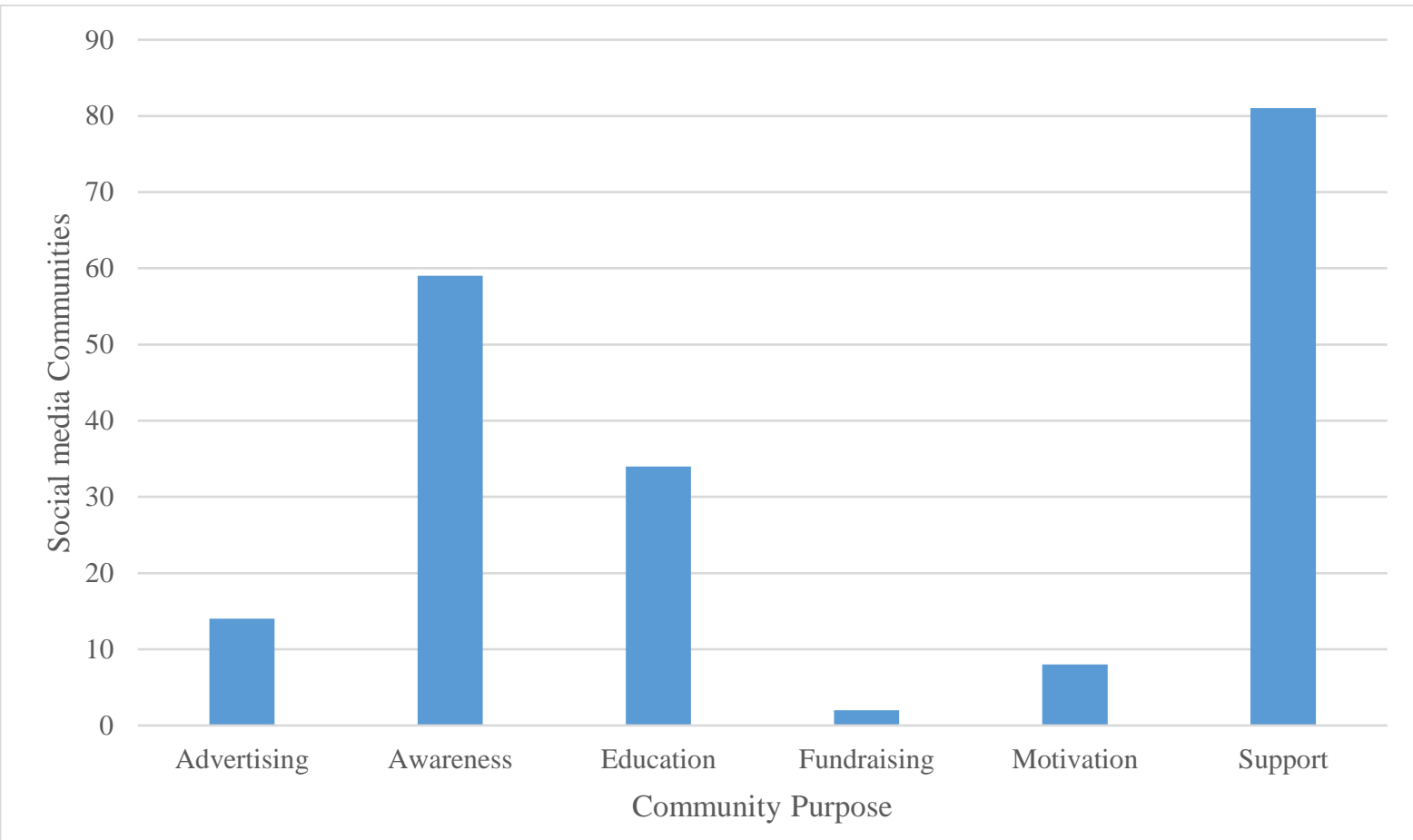

227

228 Fig 6. Social media Communities by Community Purpose and Followers

230 Table 4. Topics Identified and their Frequency of Occurrence on the Two Social Media

$231 \quad$ Platforms

\begin{tabular}{|l|c|c|}
\hline Information Topics & Frequency & Percentage (\%) \\
\hline GENERAL & 4609 & 66.90 \\
\hline What is Stroke? & 89 & 1.29 \\
\hline Signs and Symptoms & 753 & 10.93 \\
\hline Types of Stroke & 112 & 1.63 \\
\hline Causes of Stroke & 54 & 0.78 \\
\hline Diagnosis & 20 & 0.29 \\
\hline Risk Factors & 1011 & 14.68 \\
\hline Demographics & 122 & 1.77 \\
\hline Heart and Vascular Health & 714 & 10.36 \\
\hline Mental Health & 46 & 0.67 \\
\hline Women's Health & 30 & 0.44 \\
\hline Lifestyle & 312 & 4.53 \\
\hline Medication & 66 & 0.96 \\
\hline Other Medical Conditions & 181 & 2.63 \\
\hline
\end{tabular}




\begin{tabular}{|c|c|c|}
\hline Diabetes & 175 & 2.54 \\
\hline Head Injury & 6 & 0.09 \\
\hline Prevention & 1310 & 19.02 \\
\hline Managing Lifestyle & 1236 & 17.94 \\
\hline Managing Mental Health & 100 & 1.45 \\
\hline Managing Medical Risks & 35 & 0.51 \\
\hline Managing Sleep & 30 & 0.44 \\
\hline Consequences & 758 & 11.00 \\
\hline Cognitive & 613 & 8.90 \\
\hline Emotional & 103 & 1.50 \\
\hline Physical & 103 & 1.50 \\
\hline Sleep & 8 & 0.12 \\
\hline Relationships & 2 & 0.03 \\
\hline Quality of Life & 2 & 0.03 \\
\hline Living and Independence & 5 & 0.07 \\
\hline Treatment & 1234 & 17.91 \\
\hline Treatment Practices & 103 & 1.50 \\
\hline Importance of Early Treatment & 83 & 1.20 \\
\hline Rehabilitation & 820 & 11.90 \\
\hline Guidelines & 454 & 6.59 \\
\hline Importance & 28 & 0.41 \\
\hline Cost & 4 & 0.06 \\
\hline At-Home Rehabilitation & 363 & 5.27 \\
\hline Treatment of Risk Factors & 305 & 4.43 \\
\hline Monitoring & 136 & 1.97 \\
\hline Surgery & 13 & 0.19 \\
\hline Medications & 204 & 2.96 \\
\hline CAREGIVER & 2280 & 33.10 \\
\hline Impact & 184 & 2.67 \\
\hline Communication Practices & 117 & 1.70 \\
\hline Health Professional & 12 & 0.17 \\
\hline Patient & 105 & 1.52 \\
\hline Roles and Decision Making & 21 & 0.30 \\
\hline Patient Support \& Care & 1195 & 17.35 \\
\hline Care Guidelines & 1077 & 15.63 \\
\hline Supporting Activities of Daily Living & 123 & 1.79 \\
\hline Finance \& Legal Support & 72 & 1.05 \\
\hline Care Planning & 162 & 2.35 \\
\hline Self-care & 864 & 12.54 \\
\hline Need & 81 & 1.18 \\
\hline Strategies & 864 & 12.54 \\
\hline Take a Break & 52 & 0.75 \\
\hline Engage in Other Activities & 105 & 1.52 \\
\hline Manage Quality-of-Life & 131 & 1.90 \\
\hline Manage Health \& Well-being & 677 & 9.83 \\
\hline Manage Emotions & 46 & 0.67 \\
\hline Manage Relationships & 48 & 0.70 \\
\hline Sharing Care Responsibilities & 55 & 0.80 \\
\hline
\end{tabular}




\section{Community Role in Information Support}

234 While community information extracted demonstrated a total of 356,960 posts, only 235173,508 posts could be extracted using a python-based scraper tool. Of these 173,508 posts, 236 the following posts were excluded: 6369 (related to motivating the individual), 16960 (focused 237 on advertising local events, products, and research), 45726 (consisted of news articles 238 regarding stroke), 25939 (included photos or videos of local community activities or events),

23928089 (focused on creating awareness for the prevention of the disease), 4176 (looked to 240 fundraise to support an individual or organization), 24672 (did not provide information 241 support), and 14070 (did not offer general stroke information or focus on caregivers). The 242 remaining 7507 posts provided the caregiver with information to support them during the care 243 trajectory, and hence were further analysed and classified as summarized in Table 4.

\section{Analysis of Interaction}

Table 5 summarizes user interaction based on the topics identified in Table 4 and

247 content type (i.e., text, image, video, and link), identified through the average of likes, shares,

248 and comments. The data presented showed that the individual's interaction with the post varied

249 based on the topic and the content type. For example, the target user group generally interacted 250 with video-based content (i.e., Likes -13.41 , Comments -8.79 and Shares -8.53 ) followed 251 by image (i.e., Likes -12.35 , Comments -4.46 and Shares -6.69 ), link (i.e., Likes -6.99 ,

252 Comments -1.59 and Shares -3.06 ) and text (i.e., Likes -4.03 , Comments -1.68 and Shares $253-2.58$ ) based content as shown in Fig 7. While the most interacted topics based on content 254 type has been illustrated in Fig 8 identified through the data summarized on Table 5. 


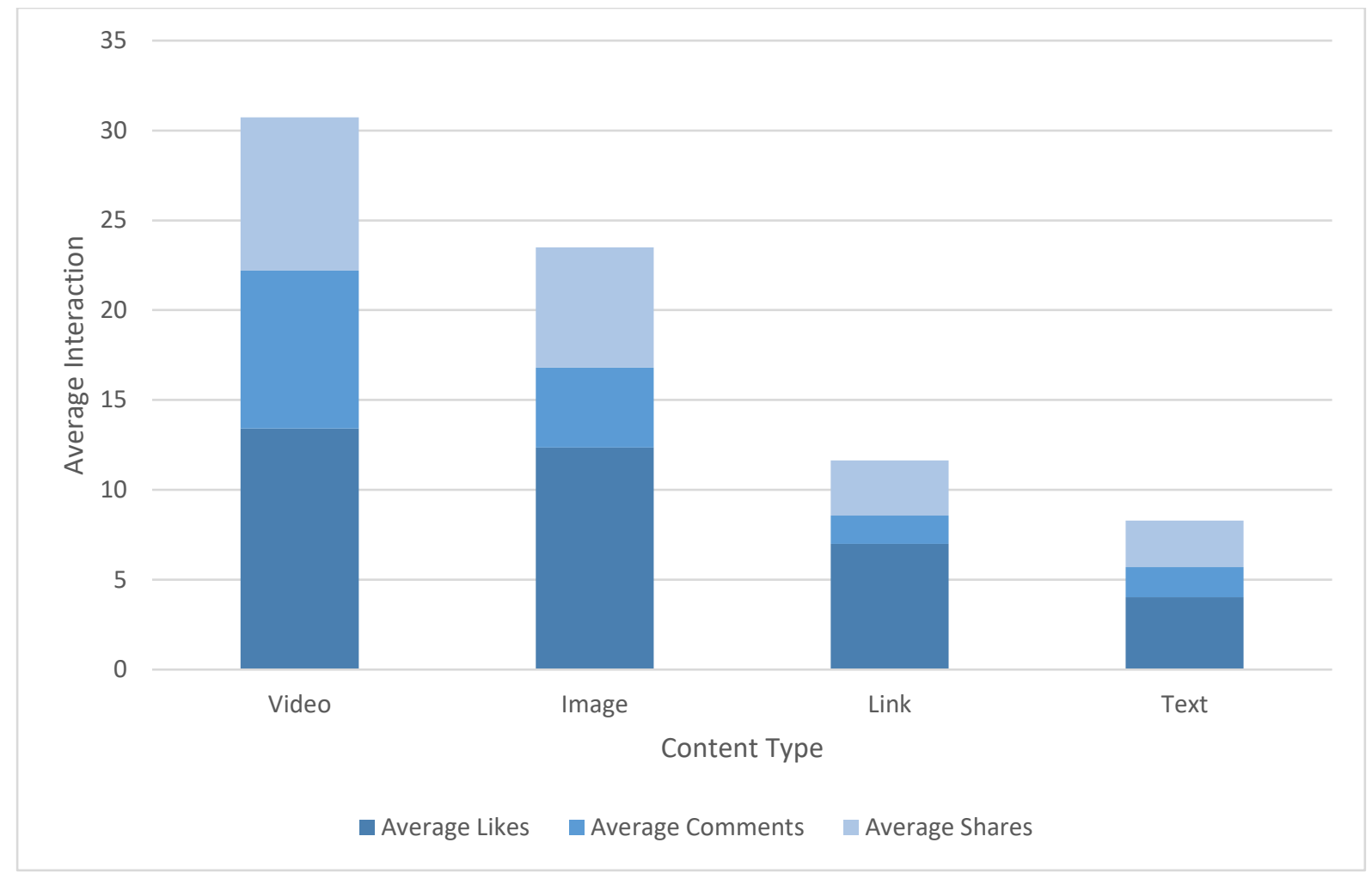

256 Fig 7. Average Interaction based on User Likes, Comments and Shares for Different

\section{Content Types}

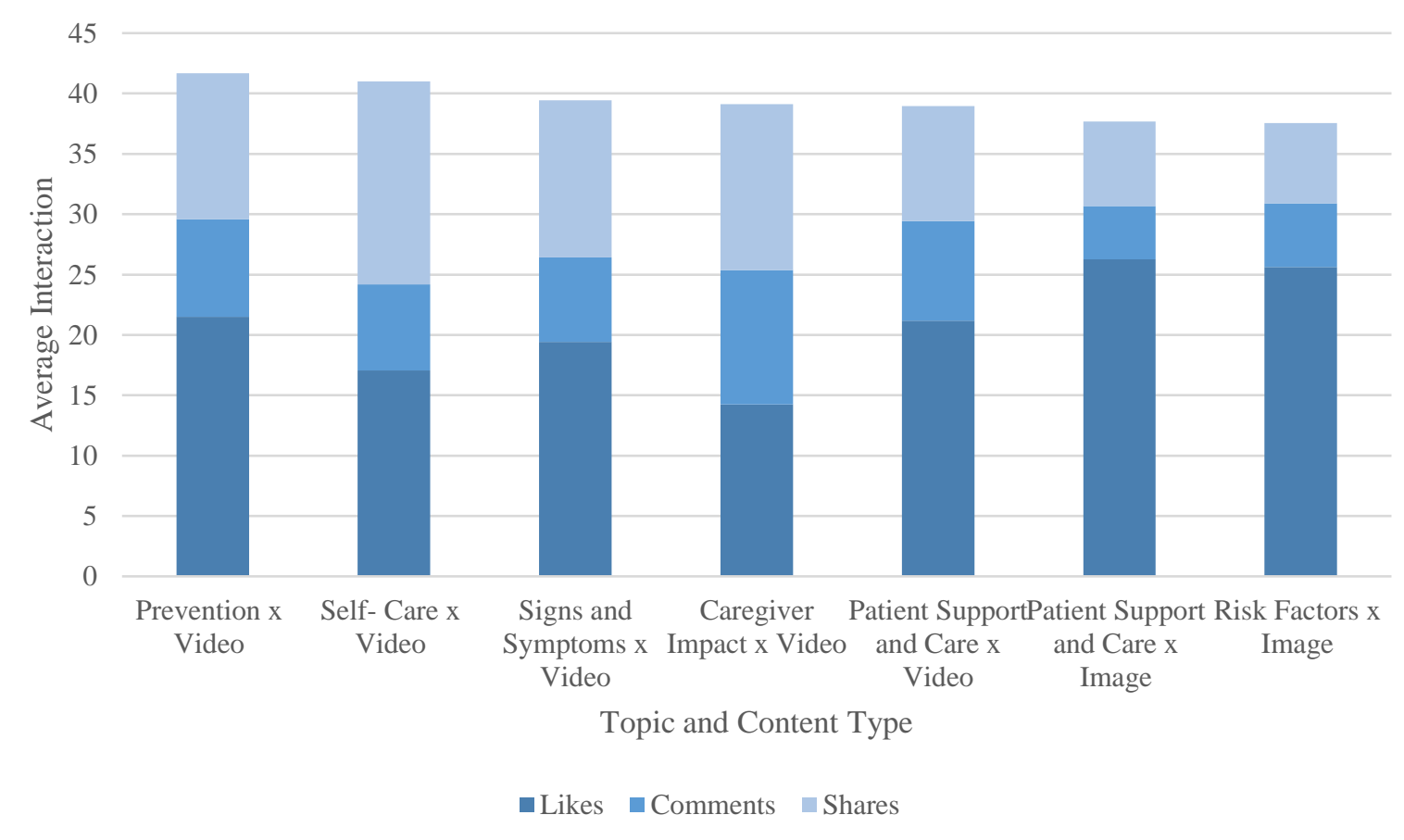

259 Fig 8. Most Interacted Topics based on Content Types 
261 Table 5 Analysis of User Interaction based on the Averages of Likes, Shares and

262 Comments for different Content Types

\begin{tabular}{|c|c|c|c|c|}
\hline Content & Type & Likes & Shares & Comments \\
\hline \multirow[t]{4}{*}{ General } & Text & 4.12 & 1.83 & 2.07 \\
\hline & Image & 13.36 & 4.35 & 6.5 \\
\hline & Video & 14.73 & 9.44 & 9.03 \\
\hline & Link & 7.39 & 1.73 & 3.49 \\
\hline \multirow[t]{4}{*}{ What is Stroke? } & Text & 0.33 & 1 & 0.33 \\
\hline & Image & 12.62 & 3.73 & 10.87 \\
\hline & Video & 1 & 0 & 0.67 \\
\hline & Link & 9 & 0.41 & 2.54 \\
\hline \multirow[t]{4}{*}{ Signs and Symptoms } & Text & 17.87 & 3.1 & 2.57 \\
\hline & Image & 13.29 & 3.6 & 11.61 \\
\hline & Video & 19.42 & 7 & 13.02 \\
\hline & Link & 9.77 & 3.96 & 8.11 \\
\hline \multirow[t]{4}{*}{ Types of Stroke } & Text & 7.75 & 1 & 6.5 \\
\hline & Image & 8.04 & 0.96 & 4.81 \\
\hline & Video & 2.71 & 0 & 1.71 \\
\hline & Link & 10.57 & 1.25 & 4.35 \\
\hline \multirow[t]{4}{*}{ Causes of Stroke } & Text & 0.67 & 0.67 & 0.67 \\
\hline & Image & 6 & 3 & 3.8 \\
\hline & Video & 8 & 0 & 7.67 \\
\hline & Link & 14.32 & 1.84 & 7.38 \\
\hline \multirow[t]{4}{*}{ Diagnosis } & Text & 2 & 0 & 0 \\
\hline & Image & 6 & 0 & 0.5 \\
\hline & Video & 0.5 & 0 & 0 \\
\hline & Link & 11.67 & 0.67 & 5.67 \\
\hline \multirow{4}{*}{ Risk Factors } & Text & 7.6 & 2.82 & 3.2 \\
\hline & Image & 25.61 & 5.28 & 6.66 \\
\hline & Video & 6.49 & 7.18 & 6.28 \\
\hline & Link & 4.54 & 2.25 & 3.67 \\
\hline \multirow[t]{4}{*}{ Prevention } & Text & 8.45 & 3.21 & 3.69 \\
\hline & Image & 18.21 & 4.13 & 5.92 \\
\hline & Video & 21.51 & 8.07 & 12.1 \\
\hline & Link & 3.54 & 1.86 & 2.56 \\
\hline \multirow[t]{4}{*}{ Consequences } & Text & 1.53 & 1.69 & 1.59 \\
\hline & Image & 9.58 & 2.63 & 4.15 \\
\hline & Video & 20.92 & 9.64 & 6.44 \\
\hline & Link & 16.57 & 1.12 & 4.28 \\
\hline \multirow[t]{4}{*}{ Treatment } & Text & 2.17 & 1.2 & 1.29 \\
\hline & Image & 11.39 & 6.39 & 7.72 \\
\hline & Video & 10.8 & 12.82 & 6.38 \\
\hline & Link & 5.46 & 0.76 & 1.99 \\
\hline
\end{tabular}




\begin{tabular}{|c|l|c|c|c|}
\hline Caregiver & Text & 2.73 & 1.96 & 2.3 \\
\cline { 2 - 5 } & Image & 15.68 & 3.95 & 5.38 \\
\cline { 2 - 5 } & Video & 19 & 8 & 1.18 \\
\cline { 2 - 5 } & Link & 5.94 & 1.5 & 2.43 \\
\hline \multirow{4}{*}{ Impact } & Text & 2.67 & 0 & 0.67 \\
\cline { 2 - 5 } & Image & 6.19 & 3.3 & 3.11 \\
\cline { 2 - 5 } & Video & 14.25 & 11.13 & 13.75 \\
\cline { 2 - 5 } & Link & 15.1 & 2.15 & 4.1 \\
\hline \multirow{5}{*}{ Communication Practices } & Text & 2 & 1.83 & 1.67 \\
\cline { 2 - 5 } & Image & 4.94 & 3.06 & 4.44 \\
\cline { 2 - 5 } & Video & 11.4 & 7.6 & 4.4 \\
\cline { 2 - 5 } & Link & 4.67 & 0.72 & 1.4 \\
\hline Roles and Decision Making & Text & 0 & 0 & 0 \\
\cline { 2 - 5 } & Image & 0 & 0 & 0 \\
\cline { 2 - 5 } & Video & 0 & 0 & 0 \\
\cline { 2 - 5 } & Link & 3 & 0.35 & 2.25 \\
\hline Patient Support \& Care & Text & 2.34 & 1.49 & 1.97 \\
\cline { 2 - 5 } & Image & 26.25 & 4.43 & 7.01 \\
\cline { 2 - 5 } & Video & 21.19 & 8.23 & 9.54 \\
\cline { 2 - 5 } & Link & 4.18 & 1 & 2.04 \\
\hline \multirow{5}{*}{ Self-care } & Text & 4.05 & 2.9 & 3.45 \\
\cline { 2 - 5 } & Image & 4.2 & 3.42 & 3.58 \\
\cline { 2 - 5 } & Video & 17.06 & 7.12 & 16.82 \\
\cline { 2 - 5 } & Link & 6.86 & 2.14 & 2.93 \\
\hline
\end{tabular}

\section{Discussion}

This study aims to highlight the information-seeking behaviour of people affected by stroke and the interaction of content created for caregivers on popular social media platforms (i.e.,

267 Facebook and Twitter). This study is significant for content creators of social media communities to identify appropriate topics to support stroke caregiving needs and promote caregiver interaction within the community, thereby ensuring caregiver education and 270 preparedness when supporting the survivor.

Findings from our Google Insights show an increase in search trends for stroke-related topics over the past ten years. The growth has been predominately for topics related to the signs and symptoms and medications, with stroke definition and recovery being the most popular searches over the past ten years. This concurs with Tan and Goonawardene [23], which 
275 suggests an increase in users seeking health information online to ensure education and 276 preparedness for the disease, thereby allowing them to make better healthcare decisions during 277 recovery.

The increase in user access to internet resources for stroke was not limited to Google searches but also within popular social media platforms. The findings from the study show an increase in social media communities for caregivers post-2009 created by individuals with different affiliations. A majority of which are individuals and charitable organizations. However, the most accessed social media communities were found to be affiliated with governmental and charitable organizations. This could be due to the trust factor associated with information provided by federal agencies and community organizations, as highlighted in the study by Dutta-Bergman [24], suggesting that the information provided by these individuals is based on expert-based literature and credible sources.

Nowadays, misinformation or lack of quality information is a growing problem [25]. Crocco, Villasis-Keever [26] in a systematic review highlighted the internet's capacity to harm the health of the user to be equal to the good and useful information it provides in a relatively timely and inexpensive manner. For example, in one case the misinformation available on the internet contributed to emotional harm, while in another case lead to hepatorenal failure in an oncology patient who obtained misinformation regarding medication use over the internet [26].

293 To prevent healthcare issues and fears amongst the population, Cuan-Baltazar, Muñoz-Perez 294 [25] suggests the need for governmental organizations to develop a strategy that teaches its residents to verify the quality of information they read. Moreover, Swire-Thompson and Lazer

296 [27] describes the need for internet users to collaborate with physicians to ensure they are more 297 actively involved in the decision-making processes, and they are aware of methods to separate 298 health myths from facts that the internet provides. 
299 While social media communities do not exclusively focus on the caregiver, it was possible

300 to identify the relevant communities and posts through their content, which were classified in

301 this study based on their relevance. The classification involved two categories; (i) General, i.e.,

302 posts that enabled the caregiver to understand the disease, causes, types, diagnosis methods,

303 risk factors, prevention, consequences, and treatment, and (ii) Caregiver, i.e., information to

304 enable the caregiver to communicate with relevant stakeholders, understand the impact of

305 caregiving, understand the roles and decision making practices, understand means to support

306 and care for the patient and to ensure self-care. Overall, findings from these comments

307 highlight a positive interaction in terms of likes, shares, and comments, especially for video-

308 based content and topics related to prevention, self-care, signs and symptoms, caregiver impact,

309 and patient support and care.

310 Video-based education resources have numerous advantages to promote positive health

311 decisions and lifestyle changes [28]. The benefits include: (i) cost-effectiveness, (ii) removal

312 of inconsistencies and presentation of information in a standardized format, (iii) creation of

313 content that allows individuals with low health literacy to comprehend health information, and

314 (iv) access through numerous different platforms or interventions [29]. However, Ferguson

315 [28] highlights the importance of presenting the content concisely to avoid overwhelming the

316 target audience with information, with a specific focus on the video length to ensure

317 attentiveness of the target audience during the duration of the video.

318 While this study suggests caregivers in the stroke generally prefer video-based resources

319 on social media communities, it is crucial to understand the influences of other media like text

320 and images on health education. For instance, text-based resources allow individuals to access

321 materials at their own pace and may be easier to access than video-based resources, particularly

322 for individuals with low technical literacy [29]. On the other hand, images benefit individuals 
323 with low literacy skills [30] and have enhanced comprehension, satisfaction, and readability

324 amongst the target audience [31].

Given that information type (i.e., video, image, and text) is a critical aspect for delivering information to specific individuals, it is also equally essential for one to consider individuals' needs to maximize interaction. Despite the existing set of topics that researchers believe to be important to address specific health information needs, there are several differences in the actual individual's needs [32]. For example, researchers are influenced by the disease type and researcher's motivation [32], while in stroke caregiving, the caregiver's needs differ based on the different stages of the survivors' illness, the need to maintain care continuum, and to ensure self-care during recovery $[7,33]$. The need to maintain a care continuum and ensure self-care was evident in this study, with maximum interaction identified in prevention, signs \& symptoms, patient support \& care, risk factors, caregiver impact, and self-care. However, greater emphasis would need to be considered to provide information at different stages of the survivors' illness, which is currently not evident. In addition, it is important to understand the literacy and communication barriers that may impact the target audience and may limit their motivation to engage with the information, which can be restricted by co-designing information to limit these barriers [30].

One method that can be implemented when designing health information is Participatory Design (or PD) approach [34]. The PD approach has been drawn from several methods, theories, and evidence from multiple disciplines such as human factors, marketing, engineering, sociology, and health [35]. This approach aims to actively involve different stakeholders with the intention to understand their needs and barriers towards creating meaningful, actionable, and feasible knowledge [34,36], thereby enhancing communication and enriching the health information designed [37]. Hence, making it an ideal methodology for co-designing information in stroke caregiving. 


\section{Study Limitations}

350 The study was focused on understanding the information-seeking behaviour, types of

351 information available, and interaction of caregivers online through Google Insights and

352 Content Analysis of popular social media platforms. During the analysis process, several

353 limitations arose. First, the inability of the scraper tool developed to extract all the posts from

354 the social media community due to the particular restrictions by the social media platforms that

355 monitor programs accessing social media content and blocking its access. Further, several posts

356 were excluded during the filtration process if they did not include the target audience, i.e., the

357 caregiver. These limitations may have resulted in several excluded posts that may have

358 supported the caregiver during their care process. Second, the user interaction analysis

359 considered the likes, shares, and comments of all audiences within the community as it was

360 impossible to segregate the users based on their role. If the posts were segregated based on the

361 type of user, the outcomes might demonstrate a difference in caregiver information needs and

362 their level of interaction on the popular social media platforms. Third, the search criterion was

363 limited to only English, and we are unsure if the inclusion of non-English communities may

364 impact the outcomes of the findings. Finally, the exclusion of communities that are not publicly

365 accessible. We excluded these communities due to ethical considerations and privacy. As a

366 result, we are unsure if the discussions within these communities would provide a

367 comprehensive understanding of the health information needs of caregivers and their levels of

368 interaction. 
370

371

372

373

374

375

376

377

378

379

380

381

382

\section{Conflicts of Interest}

384 The authors declare that they have no conflict of interest

\section{Conclusions} are prepared throughout the care process.

The study investigated the information-seeking behavior on Google and the content and user interaction on popular social media platforms. Findings suggest that there is a significant rise in online searches over the past ten years in stroke. The surge is indicated on both Google and social media communities. On analysis of comments designed explicitly for caregivers, topics related to the continuum of care and self-care were most engaging, especially in videobased formats. However, content creators need to understand the influences of information needs and delivery to maximize user interaction. This may be possible through co-design practices such as participatory design, which has in the past demonstrated efficient results in enhancing communication practices and enriching health information quality. Therefore, creating a deeper understanding of the caregiver and necessary information topics ensures they 
392 Iranian patients with stroke: a randomized controlled trial study. Aging clinical and

393

394

395

396

397

398

399

400

401

402

403

404

405

406

407

408

409

410

411

412

413

414

415

416

417

418

419

420

421

422

423

424

425

426

427

428

429

430

431

432

433

434

435

436

437

438

439 experimental research. $2020 \mathrm{Jul} ; 32(7): 1343-52$. doi: 10.1007/s40520-019-01321-4.

2. Kumar R, Kaur S, Reddemma K. Family needs of caregivers of stroke survivors. Adv Practice Nurs. 2016;1(120):2.

3. McCurley JL, Funes CJ, Zale EL, Lin A, Jacobo M, Jacobs JM, et al. Preventing Chronic Emotional Distress in Stroke Survivors and Their Informal Caregivers. Neurocritical Care. 2019 2019/06/01;30(3):581-9. doi: 10.1007/s12028-018-0641-6.

4. Mores G, Whiteman RM, Ploeg J, Knobl P, Cahn M, Klaponski L, et al. An Evaluation of the Family Informal Caregiver Stroke Self-Management Program. The Canadian journal of neurological sciences Le journal canadien des sciences neurologiques. 2018 Nov;45(6):660-8. doi: 10.1017/cjn.2018.335.

5. Lutz BJ, Young ME, Creasy KR, Martz C, Eisenbrandt L, Brunny JN, et al. Improving Stroke Caregiver Readiness for Transition From Inpatient Rehabilitation to Home. The Gerontologist. 2017 Oct 1;57(5):880-9. PMID: PMC5881730. doi: 10.1093/geront/gnw135.

6. Lobo EH, Frølich A, Rasmussen LJ, Livingston PM, Grundy J, Abdelrazek M, et al. Understanding the Methodological Issues and Solutions in the Research Design of Stroke Caregiving Technology. Frontiers in public health. 2021;9:647249. PMID: PMC8085388. doi: 10.3389/fpubh.2021.647249.

7. Tsai P-C, Yip P-K, Tai JJ, Lou M-F. Needs of family caregivers of stroke patients: a longitudinal study of caregivers' perspectives. Patient Prefer Adherence. 2015;9:449-57. doi: 10.2147/PPA.S77713.

8. Tseung V, Jaglal SB, Salbach NM, Yoshida K, Cameron JI. Key informants' perspectives on implementing caregiver programs in an organized system of stroke care. Disability and rehabilitation. 2021 Apr;43(8):1145-52. doi: 10.1080/09638288.2019.1652704. 9. Ang SY, Tin AS, Pavitar G, Ng WM, Lee KE, Lim LH, et al. A Qualitative Study into Stroke Caregivers' Educational Needs - Perspectives of Caregivers and Healthcare Professionals. Proceedings of Singapore Healthcare. 2013 2013/09/01;22(3):166-74. doi: $10.1177 / 201010581302200303$.

10. Wu C-m. Learning to be a family caregiver for severely debilitated stroke survivors during the first year in Taiwan. Iowa City: University of Iowa; 2009.

11. Smith SD, Gignac MAM, Richardson D, Cameron JI. Differences in the experiences and support needs of family caregivers to stroke survivors: does age matter? Top Stroke Rehabil. 2008 Nov-Dec;15(6):593-601. doi: 10.1310/tsr1506-593.

12. Creasy KR, Lutz BJ, Young ME, Ford A, Martz C. The impact of interactions with providers on stroke caregivers' needs. Rehabilitation nursing : the official journal of the Association of Rehabilitation Nurses. 2013 Mar-Apr;38(2):88-98. PMID: PMC3742102. doi: 10.1002/rnj.69.

13. Danzl MM, Harrison A, Hunter EG, Kuperstein J, Sylvia V, Maddy K, et al. "A Lot of Things Passed Me by": Rural Stroke Survivors' and Caregivers' Experience of Receiving Education From Health Care Providers. The Journal of rural health : official journal of the American Rural Health Association and the National Rural Health Care Association. 2016 Winter;32(1):13-24. doi: 10.1111/jrh.12124.

14. Scantlebury A, Booth A, Hanley B. Experiences, practices and barriers to accessing health information: A qualitative study. International Journal of Medical Informatics. 2017 2017/07/01/;103:103-8. doi: 10.1016/j.ijmedinf.2017.04.018.

15. Chu JTW, Wang MP, Shen C, Viswanath K, Lam TH, Chan SSC. How, When and Why People Seek Health Information Online: Qualitative Study in Hong Kong. Interact J Med Res. 2017 2017/12/12;6(2):e24. doi: 10.2196/ijmr.7000. 
440 16. Zhao Y, Zhang J. Consumer health information seeking in social media: a literature

441 review. Health information and libraries journal. 2017 Dec;34(4):268-83. doi: 442 10.1111/hir.12192.

443 17. Naqvi IA, Montiel TC, Bittar Y, Hunter N, Okpala M, Johnson C, et al. Internet Access 444 and Usage Among Stroke Survivors and Their Informal Caregivers: Cross-sectional Study. 445

446

447

448 JMIR Form Res. 2021 2021/3/8;5(3):e25123. doi: 10.2196/25123.

18. Li Y, Wang X, Lin X, Hajli M. Seeking and sharing health information on social media: A net valence model and cross-cultural comparison. Technological Forecasting and Social Change. 2018 2018/01/01/;126:28-40. doi: 10.1016/j.techfore.2016.07.021.

449 19. Zhou L, Zhang D, Yang CC, Wang Y. Harnessing social media for health information 450 management. Electronic Commerce Research and Applications. 2018 2018/01/01/;27:139-51. 451 doi: 10.1016/j.elerap.2017.12.003.

452 20. Cabrera-Maqueda Jose M, Minhas Jatinder S. New Horizons for Stroke Medicine: 453 Understanding the Value of Social Media. Stroke. 2018 2018/02/01;49(2):e25-e7. doi: 454 10.1161/STROKEAHA.117.020068.

455 21. Schoonenboom J, Johnson RB. How to Construct a Mixed Methods Research Design. Kolner Z Soz Sozpsychol. 2017;69(Suppl 2):107-31. doi: 10.1007/s11577-017-0454-1.

22. Thomas J, Harden A. Methods for the thematic synthesis of qualitative research in systematic reviews. BMC Med Res Methodol. 2008 Jul 10;8:45. PMID: PMC2478656. doi: $10.1186 / 1471-2288-8-45$.

460 23. Tan SS, Goonawardene N. Internet Health Information Seeking and the Patient461 Physician Relationship: A Systematic Review. Journal of medical Internet research. 2017 Jan 19;19(1):e9. PMID: PMC5290294. doi: 10.2196/jmir.5729.

24. Dutta-Bergman M. Trusted online sources of health information: differences in demographics, health beliefs, and health-information orientation. Journal of medical Internet research. 2003 Jul-Sep;5(3):e21. PMID: PMC1550562. doi: 10.2196/jmir.5.3.e21.

25. Cuan-Baltazar JY, Muñoz-Perez MJ, Robledo-Vega C, Pérez-Zepeda MF, Soto-Vega E. Misinformation of COVID-19 on the Internet: Infodemiology Study. JMIR public health and surveillance. 2020 Apr 9;6(2):e18444. PMID: PMC7147328. doi: 10.2196/18444.

26. Crocco AG, Villasis-Keever M, Jadad AR. Analysis of cases of harm associated with use of health information on the internet. Jama. 2002 Jun 5;287(21):2869-71. doi: 10.1001/jama.287.21.2869.

27. Swire-Thompson B, Lazer D. Public Health and Online Misinformation: Challenges and Recommendations. Annual review of public health. 2020 Apr 2;41:433-51. doi: 10.1146/annurev-publhealth-040119-094127.

28. Ferguson LA. Implementing a Video Education Program to Improve Health Literacy. The Journal for Nurse Practitioners. 2012 2012/09/01/;8(8):e17-e22. doi: 10.1016/j.nurpra.2012.07.025.

29. Tuong W, Larsen ER, Armstrong AW. Videos to influence: a systematic review of effectiveness of video-based education in modifying health behaviors. Journal of behavioral medicine. 2014 Apr;37(2):218-33. doi: 10.1007/s10865-012-9480-7.

481 30. van Beusekom MM, Grootens-Wiegers P, Bos MJ, Guchelaar HJ, van den Broek JM. 482 Low literacy and written drug information: information-seeking, leaflet evaluation and 483 preferences, and roles for images. International journal of clinical pharmacy. 2016 484 Dec;38(6):1372-9. PMID: PMC5124048. doi: 10.1007/s11096-016-0376-4.

485 31. Lühnen J, Steckelberg A, Buhse S. Pictures in health information and their pitfalls: 486 Focus group study and systematic review. Zeitschrift fur Evidenz, Fortbildung und Qualitat im Gesundheitswesen. 2018 Nov;137-138:77-89. doi: 10.1016/j.zefq.2018.08.002. 
488 32. Pian W, Song S, Zhang Y. Consumer health information needs: A systematic review of 489 measures. Information Processing \& Management. 2020 2020/03/01/;57(2):102077. doi: 490 10.1016/j.ipm.2019.102077.

491 33. Pierce LL, Gordon M, Steiner V. Families dealing with stroke desire information about 492 self-care needs. Rehabilitation nursing : the official journal of the Association of Rehabilitation 493 Nurses. 2004 Jan-Feb;29(1):14-7. doi: 10.1002/j.2048-7940.2004.tb00294.x.

494 34. Smith F, Wallengren C, Öhlén J. Participatory design in education materials in a health 495 care context. Action Research. 2016 2017/09/01;15(3):310-36. doi: $496 \quad 10.1177 / 1476750316646832$.

497 35. Neuhauser L, Rothschild B, Graham C, Ivey SL, Konishi S. Participatory design of 498 mass health communication in three languages for seniors and people with disabilities on 499 Medicaid. American journal of public health. 2009 Dec;99(12):2188-95. PMID: PMC2775764. 500 doi: 10.2105/ajph.2008.155648.

501 36. Andersen TO, Bansler JP, Kensing F, Moll J, Mønsted T, Nielsen KD, et al. Aligning 502 Concerns in Telecare: Three Concepts to Guide the Design of Patient-Centred E-Health. 503 Comput Supported Coop Work. 2019 2019/10/01;28(6):1039-72. doi: 10.1007/s10606-018504 9309-1.

505 37. Paulovich B. Design to Improve the Health Education Experience: using participatory 506 design methods in hospitals with clinicians and patients. Visible Language. 2015 $507 \quad 04 / / ; 49(1 / 2): 144-59$.

508

509 Supporting Information

510 S1 File. Keywords Searched in Google Trends and Insights

511 S2 File. Included Social Media Communities

512 S3 File. Included Community Posts and User Interactions 